\title{
Bufo bufo (Common toad): Predation by the medicinal leech (Hiruda medicinalis)
}

\author{
DAVID BULL
}

\author{
34 Gatcombe, Netley Abbey, Southampton, Hampshire, SO31 5PX, UK \\ Author e-mail: bull77@btinternet.com
}

\begin{abstract}
Interactions between amphibians and invertebrate predators and parasites are important aspects of amphibian ecology. Presented here are observations of medicinal leechs (Hirudu medicinalis) feeding on common toads (Bufo bufo) that had congregated for spawning in a pond in the New Forest, southern England. A medicinal leech was observed to be attached to the head of a male toad that was in amplexus with a female. A further ten $H$. medicinalis were recorded in the shallow $(<30 \mathrm{~cm}$ deep) flooded grasses at the pond margin. Eight were free swimming and two were attached to the female of a second pair of toads that were in amplexus, one to the head of the female and one to the rear leg of the female (Fig. 1). Water temperature was $15^{\circ} \mathrm{C}$, air temperature was $15-16^{\circ} \mathrm{C}$. Most leeches were about 15 $17 \mathrm{~cm}$ long but several were only about half that length. A count of emergent toad heads reached 51 and observation of the shallow marginal areas indicated that three to four times that number of toads were submerged and passive in or on the vegetation.
\end{abstract}

Over the following week, three further daytime visits and one nighttime visit was made by the author and members of a local natural history group (Table 1 ). In contrast to their behaviour during the day, all of the $\mathrm{H}$. medicinalis observed after dark were encoutered in a passive state on the bottom, but made off slowly after a brief period of illumination.

The period of $H$. medicinalis activity matched the period of toad breeding and no further $\mathrm{H}$. medicinalis were recorded during eleven subsequent daytime visits that were made by the author over the following seven months; a period in which the pond reduced greatly in area from a winter maximum of approximately $1,800 \mathrm{~m}^{2}$ of open water to less than $10 \mathrm{~m}^{2}$ in late summer. Water temperature is reported to be a major factor in leech activity (Elliott \& Kutschera, 2011) and unusually warm February temperatures in 2019 may have accounted for the observations on this occasion.

Lower water temperatures at night time may explain the lack of nocturnal activity by the leeches. The large size of $H$. medicinalis relative to its prey may result in amphibian mortality due to loss of blood (Kutschera et al., 2010). One $H$. medicinalis was attached to a dead female, but dropped off shortly after the female was recovered with no observable marks suggesting that the female was already dead when the leech encountered it. The similar species $H$. verbana has been reported to feed on dead toads (Merilä \& Sterner, 2002). Amphibians are targeted by $H$. medicinalis during

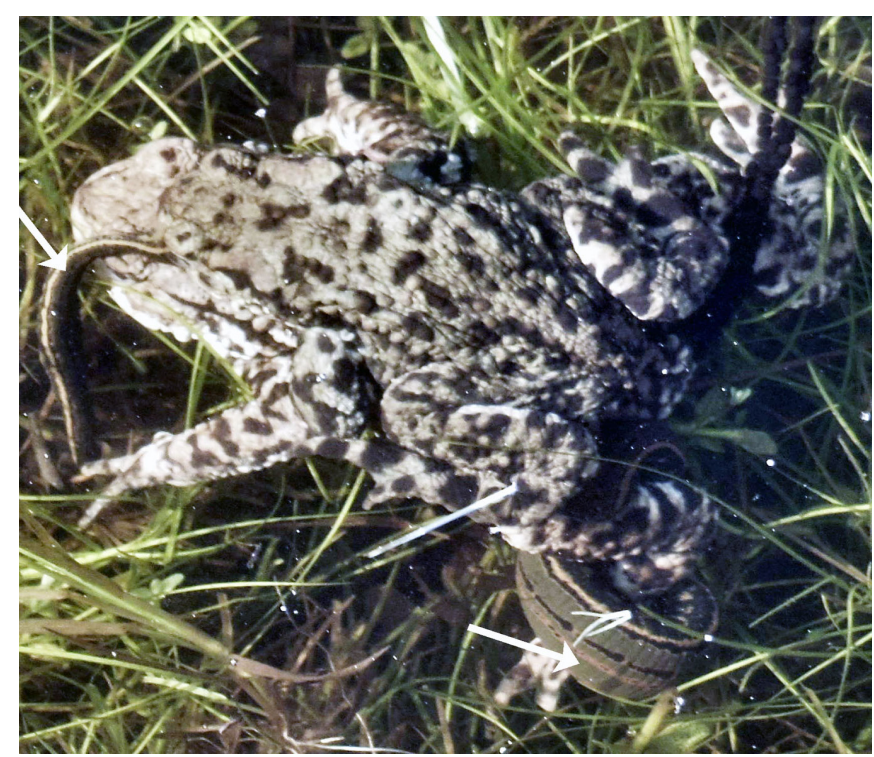

Figure 1. A pair of B. bufo in amplexus with two H. medicinalis (white arrows) attached to the female

Table 1. Details of H. medicinalis observations. Ta air temperature, Tw water temperature, ${ }^{*}$ night time survey

\begin{tabular}{|ccccll|}
\hline Date & Total & Passive & Swimming & Attached & $\mathrm{T}_{\mathrm{a}}\left({ }^{\circ} \mathrm{C}\right) \mathrm{T}_{\mathrm{w}}\left({ }^{\circ} \mathrm{C}\right)$ \\
\hline $23 / 2 / 19$ & 11 & 0 & 8 & 3 & $15-16^{\circ} 15^{\circ}$ \\
$25 / 2 / 19$ & 11 & 0 & 9 & 2 & not recorded \\
$26 / 2 / 19$ & 1 & 0 & 0 & 1 & not recorded \\
$26 / 2 / 19^{*}$ & 8 & 7 & 0 & 1 & $3.8^{\circ} \quad 9.3^{\circ}$ \\
\hline
\end{tabular}

the spring when their concentrated numbers provide a source of food for the emerging leeches (Merilä \& Sterner, 2002). However, $H$. medicinalis is now uncommon, and even protected under the Countryside \& Wildlife Act 1981 (Elliott \& Kutschera, 2011), and so consequently unlikely to have a major impact on amphibian populations. Eviscerated toad carcasses on the pond margin constitute ample evidence for toad mortality resulting from other predators. Common frogs (Rana tempora) and smooth newts (Lissotriton vulgaris) also occur at the site and may constitute an additional food source for the leeches as they have been at other sites (Frazer, 1983; Elliott \& Kutschera, 2011). Leeches are attracted to vibrations (Kutschera et al., 2010), therefore it is 
possible that the intense, short duration activity of explosive toad breeding may put them at greater risk of predation than the smaller newts that breed over a more extended period. Both the toads and leeches are recolonisers of this site which was drained during the 1950's before being reinstated in the 1990's.

\section{ACKNOWLEDGEMENTS}

I would like to thank the members of the New Forest Study Group that contributed their knowledge, experience and recollections of the site and in particular Angela Morrell, Jon Buckley and Malcom Storey for sharing their records of medicinal leeches.

\section{REFERENCES}

Elliott, J. M. \& Kutschera, U. (2011). Medicinal leeches: historical use, ecology, genetics and conservation. Freshwater Reviews 4: 21-41.
Frazer, D. (1983). Reptiles and Amphibians in Britain. London. Bloomsbury, 256 pp.

Kutschera, U., Roth, M. \& Ewert, J.P. (2010). Feeding on bufoid toads and occurrence of hyperparasitism in a population of the medicinal leech (Hirudo verbana Carena 1820). Research Journal of Fisheries and Hydrobiology 5: 9-13.

Merilä, J. \& Sterner, M. (2002). Medicinal leeches (Hirudo medicinalis) attacking and killing adult amphibians. Annals Zoological Fenniscandia 39: 343-346. 